\title{
Evaluation of Aquifer Porosity And Hydraulic Conductivity From Empirical Equations Using Geoelectrical Sounding Measurements In Piramagroon Area NE-Iraq
}

\author{
Abdulla Karim Amin \\ Department of Social Sciences, College of Basic Education, University of Sulaimani, \\ Sulaimani, Kurdistan Region, Iraq. \\ E-mail: Abdullakarim2004@gmail.com
}

\begin{abstract}
:
Application of Vertical Electrical Sounding (VES) with Schlumberger array as a low-cost technique and veritable method in groundwater exploration is more suitable for hydrogeological survey of sedimentary basins. This method is regularly used to solve a wide variety of ground water problems and hydraulic parameters. The main objective of this research therefore, is to evaluate aquifer porosity and hydraulic conductivity using the empirical equations of porosity and hydraulic conductivity with resistivity conducted in the continuation of the adjacent Sharazoor basin. For this purpose, four profiles were taken in studied area (Piramagroon district), and each profile includes five VES points of measurements. Then each VES was interpreted manually as well as by IPI2 win program for determining aquifer depth ranging from $(40 \mathrm{~m}$.) to $(80 \mathrm{~m}$.) in piramagroon district $)$ and resistivity values range between $(37.0 \Omega . \mathrm{m})$ to $(102 \Omega . \mathrm{m})$, which are substituted in the empirical porosityresistivity and hydraulic conductivity-resistivity equations for evaluating aquifer porosity and hydraulic conductivity of the studied area. The estimated aquifer porosity values range along the studied area range between $(21 \%)$ to $(39 \%)$, and for hydraulic conductivity values range from ( $1 \mathrm{~m} /$ day) to $(4 \mathrm{~m} /$ day), which shows the increasing of the both aquifer porosity from the top of uplifted subsurface layers underlying the piramagroon district toward both limbs according to increasing of rock fragments (gravel, pebble) and (sand sediments) and decreasing of clay content overlying upper part of Middle Tanjero Formation.
\end{abstract}

Key Words: Aquifer Porosity $(\phi)$, Hydraulic Conductivity $(\mathrm{K}),(\phi) \&(\mathrm{~K})$ Equations, Vertical Electrical Sounding. 


\section{Introduction:}

Porosity is a measure of the amount of void space in a porous medium. It is defined as the ratio of the pore volume to the total volume of the sample and thus has no unit. When a medium contains isolated pores, the effective porosity (commonly considered to represent the pore space available for fluid flow) is less than the total porosity (De block, 2013).

The pore space is often considered in terms of individual pores-an artificial concept that enables quantifications of its essential character. Though many alternatives could serve as a basis for the definition of pores and their sizes, in soil science and hydrology these are best conceptualized, measured, and applied with respect to the fluids that occupy and move within the pore space, (Nimmo, 2004).

The development of groundwater resources and the regime of its activity largely depend on the porosity and permeability of water bearing formations. The porosity of rock is a measure of the amount of interstitial space that is capable of holding fluids and the permeability (hydraulic conductivity) of a rock is a quantitative measure of the case with which it will permit the passage of fluids through it under a hydraulic gradient. The determination of aquifer characteristics such as hydraulic conductivity and transmissivity is best made on the basis of data obtained from test pumping wells, (Batayneh, 2009).

Vukovic and Soro, (1992) noted that the applications of different empirical formulae to the same porous medium material can yield different values of hydraulic conductivity, which may differ by a factor of 10 or even 20. The objective of their research is therefore to evaluate the applicability and reliability of some of the commonly used empirical formulae for the determination of hydraulic conductivity of unconsolidated soil and rock materials. (Odong, 2007) was shown that all the results of seven empirical formulae reliably estimated hydraulic conductivities of the various soil samples well within the known ranges.

Urumovic, K, and Urumovic, S. K, (2016) objective of their article is to research the relationship between average mean grain size and effective porosity in relation to permeability and specific surface area for a wide range of grain sizes and particle uniformities in various soil samples. In the hydraulic conductivity calculations, the Kozeny-Carman equation was used to discover the algorithm for calculating the referential mean grain size. This grain size, along with effective porosity, generates a harmonious parametric concept of the impact of porous media geometrics on its transmission capacity.

\section{Study area and field technique}

The applicable studied area known as Piramagroon district locates NE-Iraq and North West of Sulaimani city. The area was surveyed along four profiles (A, B, C and D) and conducting twenty VES-points distributed throughout the area by using symmetrical Schlumberger electrode arrangement, as shown in Fig.(1). 


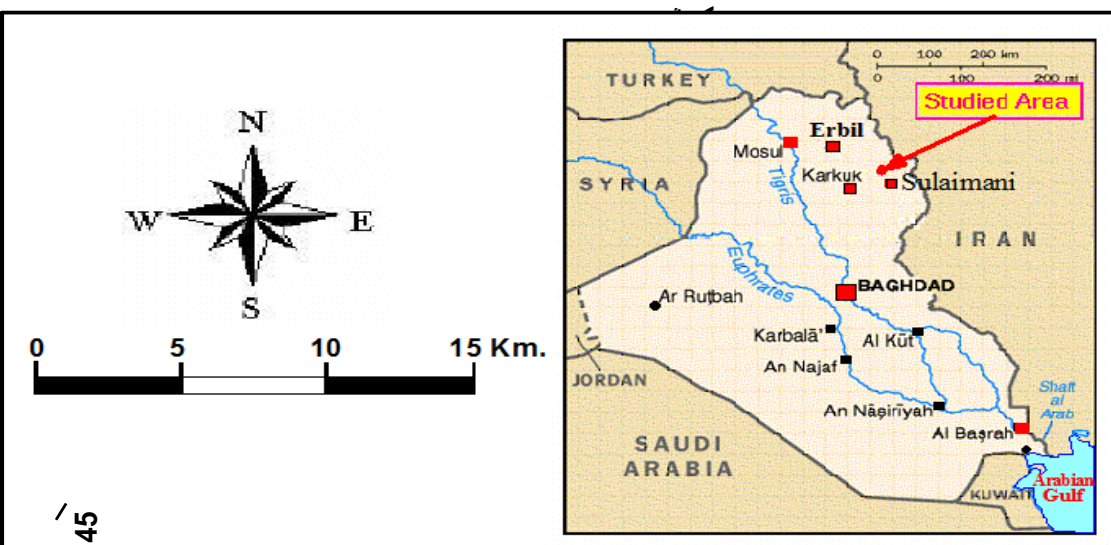

7130 P-ISSN: 2410 - 1036

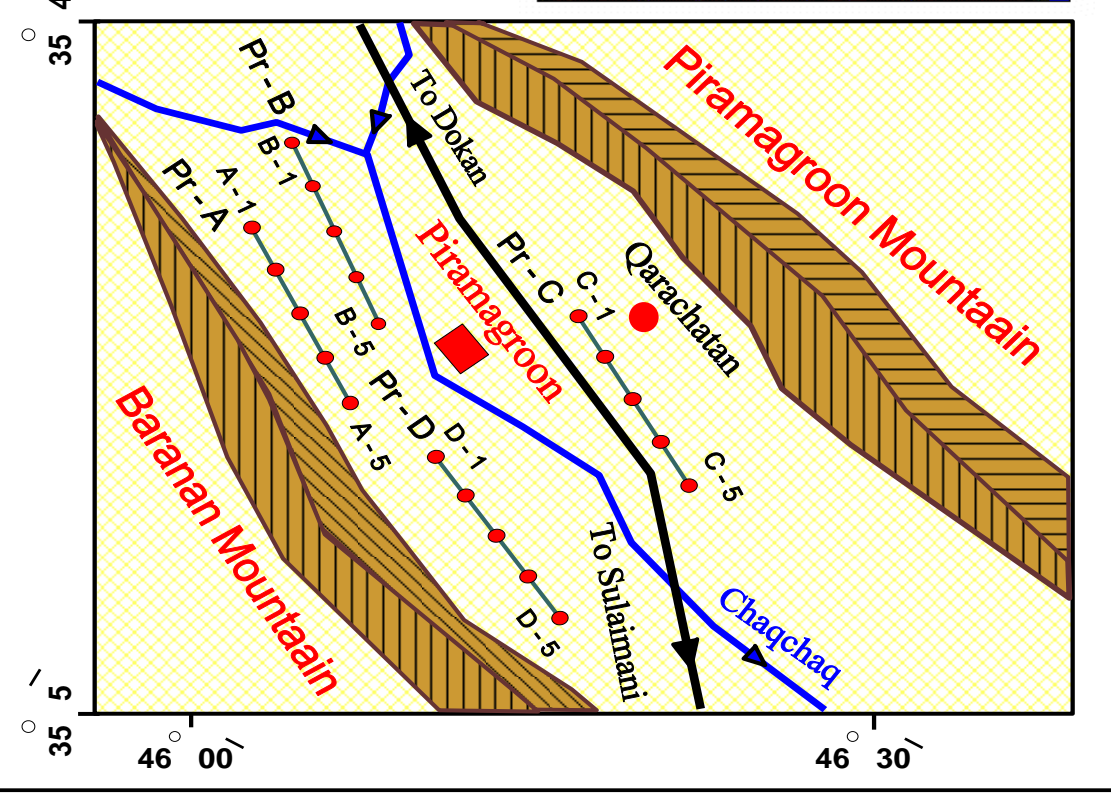

Fig. (1) Location map of studied area with the surveying profile drawn

Measurements of VES-points were taken by modern computerized static resistivity meter (SYSCAL Jr-Switch72) type as shown in fig.(2), with the half length of spread $(\mathrm{AB} / 2=500 \mathrm{~m}$.) and $(\mathrm{MN} / 2=80 \mathrm{~m}$.) in order to increase depth of penetration to required depth possible to detect layers depths and thicknesses as well as corresponding resistivities. The instrument is a new multimode combined system of switching unit (link box, current transducer, potentiometer with attached rechargeable battery). The instrument is controlled by a microprocessor for conducting one and two dimensional electrical resistivity survey by using of (Wenner, Schlumberger and Dipole-Dipole) or any other arrangement. It can be also used for conducting Spontaneous polarization (SP) method and induced polarization. 


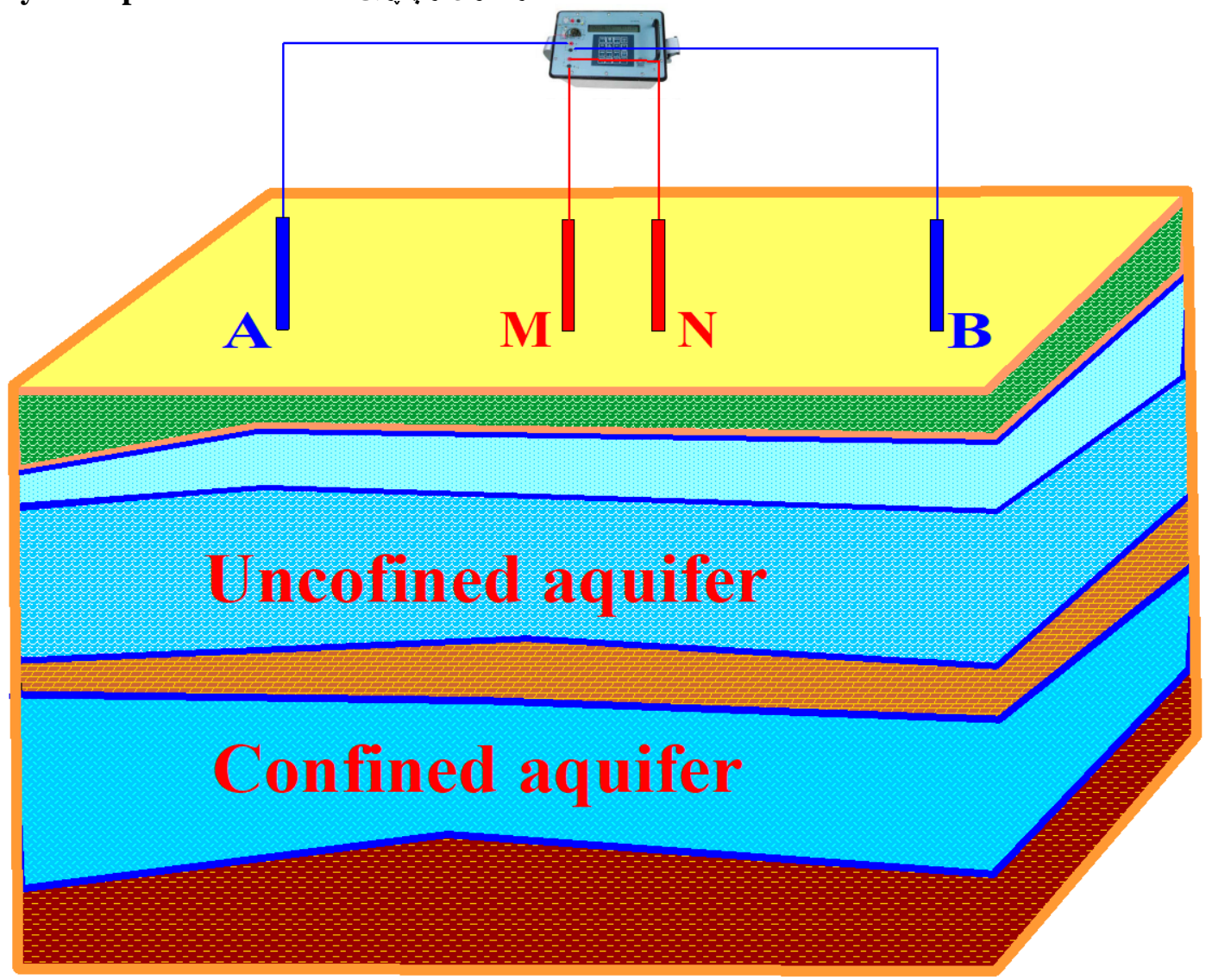

Fig. (2) Modern computerized static resistivity meter (SYSCAL Jr-Switch-72) drawn by Surfer 8, 2002

\section{Theoretical formulas for aquifer porosity $(\phi)$ and hydraulic conductivity estimation}

\subsection{Formulas for aquifer porosity $(\phi)$ estimation}

The porosity of a rock or soil is a measure of the contained interstices or void expressed as the ratio of the volume of interstices to the total volume, (Todd and Mays, 2005), if $(\phi)$ is porosity, then:-

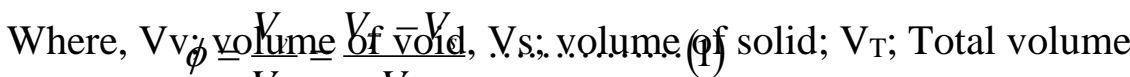

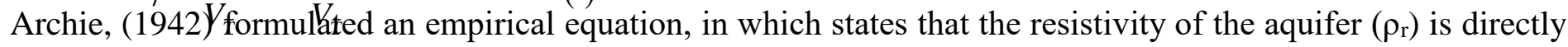
proportional to the resistivity of the water $\left(\rho_{\mathrm{w}}\right)$ filling the pores of the sand stone Formation, the proportionality constant $(\mathrm{F})$ is known as the formation factor as follow:-

$$
\rho_{r} \alpha \rho_{w}
$$

So that:-

$$
\rho_{r}=F \rho_{w}
$$

$$
F=\frac{\rho_{r}}{\rho_{r}}
$$

According to the Archieformula the porosity $(\phi)$ and Formation factor $(F)$ relationship is given by:-

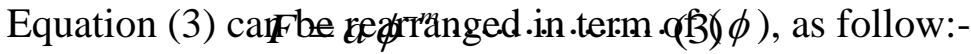

$$
\begin{aligned}
\phi^{-m} & =\frac{F}{a} \\
\frac{1}{\phi^{m}} & =\frac{F}{a}
\end{aligned}
$$


By powering both sides of the Eq. to $\left(\frac{1}{m}\right)$ :-

$$
\begin{gathered}
\left(\phi^{m}\right)^{\frac{1}{m}}=\left(\frac{a}{F}\right)^{\frac{1}{m}} \\
\phi=\left(\frac{a}{F}\right)^{1 / m} \ldots . .
\end{gathered}
$$

Vukovic and Soro,(1992) were put an empirical formula for estimating hydraulic conductivity from porosity presented in a general formula:-

Where:-

$$
K=\frac{g}{v} \cdot c \cdot f(n) \cdot d_{e}^{2}
$$

$K=$ hydraulic conductivity

$v=$ kinematics viscosity

$f(n)=$ porosity function,

$g=$ acceleration due to gravity

$C=$ sorting coefficient;

$d_{e}=$ effective grain diameter.

The kinematics viscosity $(v)$ is related to dynamic viscosity $(\mu)$ and the fluid (water) density $(\rho)$ as follows:

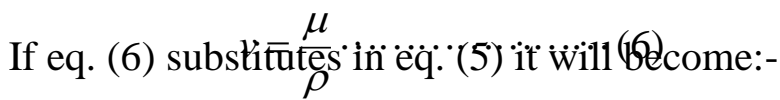

$$
K=\frac{\rho \cdot g}{\mu} \cdot c \cdot f(n) \cdot d_{e}^{2}
$$

Eq. (7) can be put in form of porosity function $f(n)$ as follow:-

$$
f(n)=\frac{K \cdot \mu}{\rho \cdot g} c . d_{e}^{2}
$$

Eq. (8) can be used for porosity estimation in case of knowing hydraulic conductivity (K) and both values of (C) and $\left(\mathrm{d}_{\mathrm{e}}\right)$ are dependent on the different methods used in the grain-size analysis, and density of water is taken as ( $\rho$ $=1000 \mathrm{~kg} / \mathrm{m}^{3}$ ), so this technique is also limited because it needs to know all the above mentioned parameters which will lead to restrict its application.

Typical range values of gravel with sand modified from (Kruseman and De Ridder, 1994; Bernard, 2003) as shown in Table (1).

Table (1) Typical values of porosity ranges within gravel, sand and sandstone

\begin{tabular}{|c||c|}
\hline Materials and Rocks & Porosity $(\phi \%)$ \\
\hline \hline Soils & $50-60$ \\
\hline \hline Clay & $45-55$ \\
\hline \hline Silt & $40-50$ \\
\hline \hline Medium to coarse mixed sand & $35-45$ \\
\hline \hline Fine to medium mixed sand & $30-40$ \\
\hline \hline Uniform sand & $30-35$ \\
\hline \hline Gravel & $30-40$ \\
\hline \hline Gravel with sand & $20-35$ \\
\hline \hline Sandstone & $10-20$ \\
\hline Shale & $1-10$ \\
\hline
\end{tabular}




\subsection{Formulas for aquifer hydraulic conductivity (K) estimation}

Hydraulic conductivity of the sediments or rock is a measure of the ability of geologic unit (media) to transmit water, which is a function of both the medium and the fluid properties (Fetter, 1998). Whereas (Deming, 2002) had been returned hydraulic conductivity to a variety of physical factors, including porosity, particle size and distribution, shape of particles, arrangement of particles and other factors.

Transmissivity ( $\mathrm{T}$ ) can be calculated by conducting pumping test, through which Hydraulic conductivity (K) can be determined from calculated Transmissivity (T), by knowing the thickness of the saturated aquifer $(\mathrm{H})$, (Daves and Dewiest, 1966), according to the following equations:-

$$
T=K H
$$

Which can be expressed in term of (K), as follow:-

$$
K=\frac{T}{H}
$$

Furthermore transmissivity $(\mathrm{T})$ and hydraulic conductivity $(\mathrm{K})$ also can be determined through the applying of (AQTESOLV) software program, which is supported the obtained manual results.

(Fatoba, et al., 2014) had demonstrated in their study the efficacy of surface geophysics in estimating hydraulic characteristics of an aquifer where pumping test data are not available and also to determine its vulnerability to surface contaminants.

The basic equations for geoelectrical exploration are developed assuming that the medium is porous, the matrix is generally an insulator and electrical currents flows through the water present in the pore spaces. The aquifer's electrical resistivity is mainly influenced by porosity and fluid resistivity in the pores. The geoelectrical data recorded on the surface therefore contain useful information about the aquifer which can be interpreted by experienced geophysicists for hydrogeological studies, (Sri Niwas and Muhammed, 2012).

Since the spatial distribution of aquifer properties cannot be confidently calculated in areas with few pumping tests, determination of aquifer parameters from geoelectric sounding becomes a good alternative and costefficient technique since drilling of wells to evaluate aquifer parameters can be both expensive and timeconsuming. The range of aquifer parameters values obtained from VES interpretation is a good indication of the reliability of this method (Nicaise, et al., 2013).

The aquifer parameters values is supported by Urumovic, K, Urumovic Sr., K., (2016) through which they suggest procedures for calculating referential grain size and determining effective (flow) porosity, which result in parameters that reliably determine the specific surface area and permeability. These procedures ensure the successful application of the Kozeny - Carman model up to the limits of validity of Darcy's law. The value of effective porosity in the referential mean grain size function was calibrated within the range of $1.5 \mu \mathrm{m}$ to 6.0 $\mathrm{mm}$. The reliability of the parameters applied in the $\mathrm{KC}$ model was confirmed by a very high correlation between the predicted and tested hydraulic conductivity $\left(\mathrm{R}^{2}\right)$ values for sandy and gravelly materials is $(0.99)$, whereas for clayey-silty materials is $(0.70)$.

Sri Niwas and Lima, (2003) was concluded that electrical conductivity will be obey Archie's equation and the hydraulic conductivity can be estimated as for a single - phase conductor. Fortunately, under this condition, the aquifer would be termed saline, where electrical conductivity and hydraulic conductivity are in direct relationship, i.e. the porosity and electrical conductivity will obey a direct relationship.

Nelson, (2015) was concluded that groundwater is in constant motion, although the rate at which it moves is generally slower than it would move in a stream because it must pass through the intricate passageways between free spaces in the rock. First, the groundwater moves downward due to the pull of gravity. But it can also move upward because the water moves from high pressure zones to low pressure zones, and The velocity, V, is of groundwater flow is given by:- 


$$
V=\frac{K\left(h_{2}-h_{1}\right)}{L}
$$

where $(\mathrm{K})$ is the hydraulic conductivity, which is a measure of the permeability of the material through which the water is following, If multiply this expression by the area (A) through which the water is moving, and then we get the discharge $(\mathrm{Q})$.

$$
Q=\frac{A K\left(h_{2}-h_{1}\right)}{L}
$$

Equation (12) represents Darcy Law, which simply states that discharge is proportional to the hydraulic gradient $\left(\mathrm{A}^{*}\left(\mathrm{~h}_{2}-\mathrm{h}_{1}\right) / \mathrm{L}\right)$ times the hydraulic conductivity $(\mathrm{K})$. Note that the stream discharge $(\mathrm{Q})$ unit is $\left(\mathrm{m}^{3} / \mathrm{sec}\right.$. $)$.

The hydraulic conductivity variation due to the change of the grain size particles of unconsolidated sediments modified from (Bouwer, 1978 in Kruseman, and De Ridder, 1994), as shown in Table (2).

\begin{tabular}{|c|c|}
\hline $\begin{array}{c}\text { Unconsolidated materials and } \\
\text { rocks }\end{array}$ & $\begin{array}{c}\text { Hydraulic conductivity } \\
\text { K (m / day) }\end{array}$ \\
\hline Clay & $10^{-8}-10^{-2}$ \\
\hline Fine Sand & $1-5$ \\
\hline Medium sand & $5-20$ \\
\hline Coarse Sand & $20-100$ \\
\hline Gravel & $100-1000$ \\
\hline Sand and gravel mixes & $5-100$ \\
\hline Sandstone & $10^{-3}-1$ \\
\hline $\begin{array}{l}\text { Carbonate rock with secondary } \\
\text { porosity }\end{array}$ & $10^{-2}-1$ \\
\hline Shale & $10^{-7}$ \\
\hline Dense solid rock & $<10^{-5}$ \\
\hline
\end{tabular}

Table (2) Range of the hydraulic conductivity of unconsolidated sediments

\section{Result of interpretation field data}

The field data of VES-points along profiles were interpreted manually using partial matching by Ebert method, and then the results were interpreted with software (IPI2 win) through the applying of forward calculation and inverse modeling programs for the purpose of measuring the reliability of the results.

The (IPI2 win) program is able to modify the input parameters of the measured apparent resistivities and AB/2 values. The output results of the true resistivities and thicknesses are reflected the best fit between field curve and one of the theoretical master curves, through the applying forward calculation program.

For more accuracy results of manual interpretation, an inverse modeling was also applied by entering of the manual results of the true resistivities and thicknesses. Then best fits are obtained, through applying of iteration 
process between the field curve and master curve with minimum percent of deviations. VES-points are shown in Figures (3), (4)

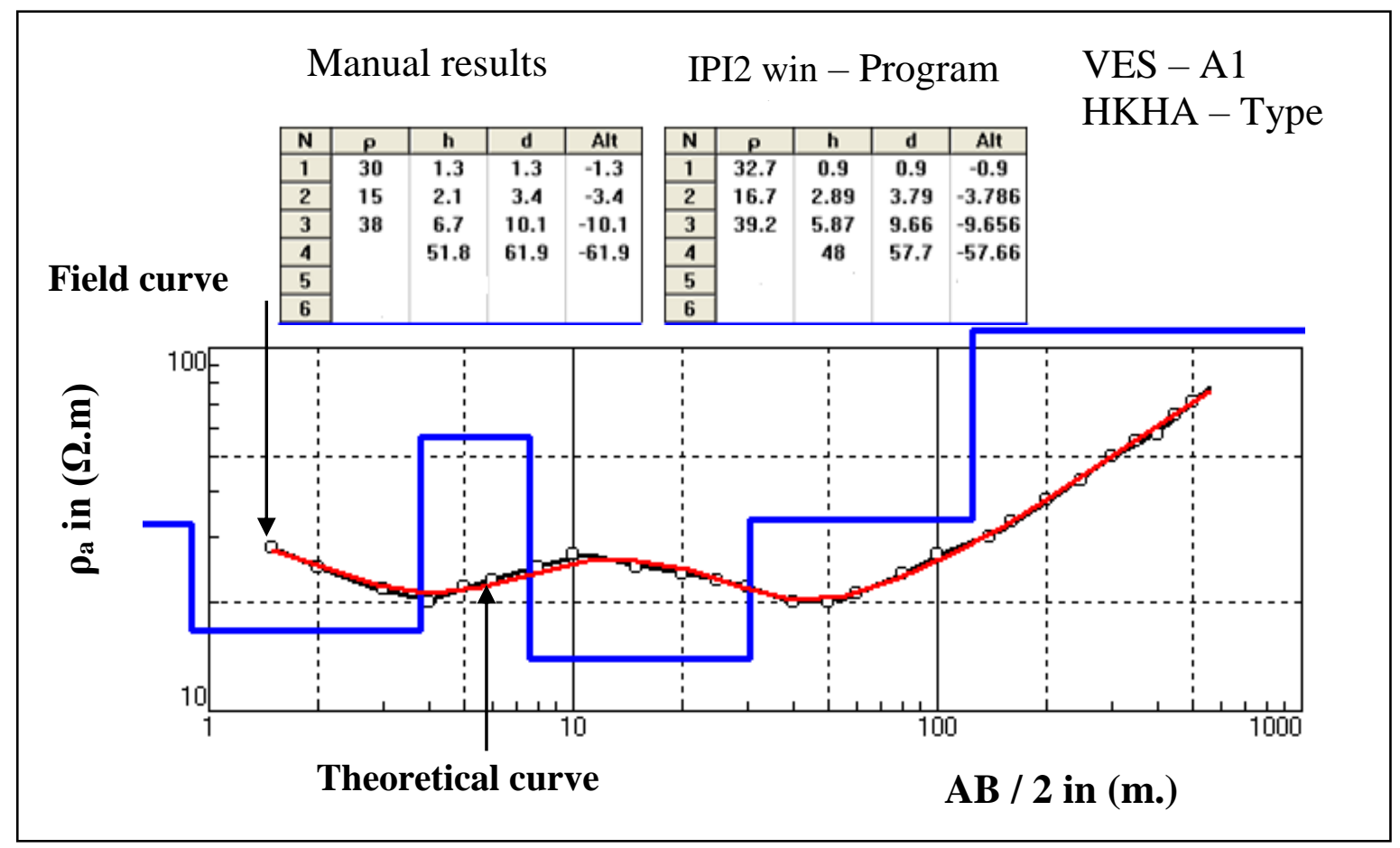

Fig.(3) Shows Inverse modeling output of IPI2 win -Software program and manual interpretation for VES - A1 of (HKHA) type

Then each VES was interpreted manually as well as by IPI2 win program, through which the results reveal that the aquifer depth ranging from $(40 \mathrm{~m}$.) in piramagroon district to more than $(80 \mathrm{~m}$.). as well as reaiativity values range between (37 $\Omega . m)$ to (102 $\Omega . m)$, as shown in Table (3).

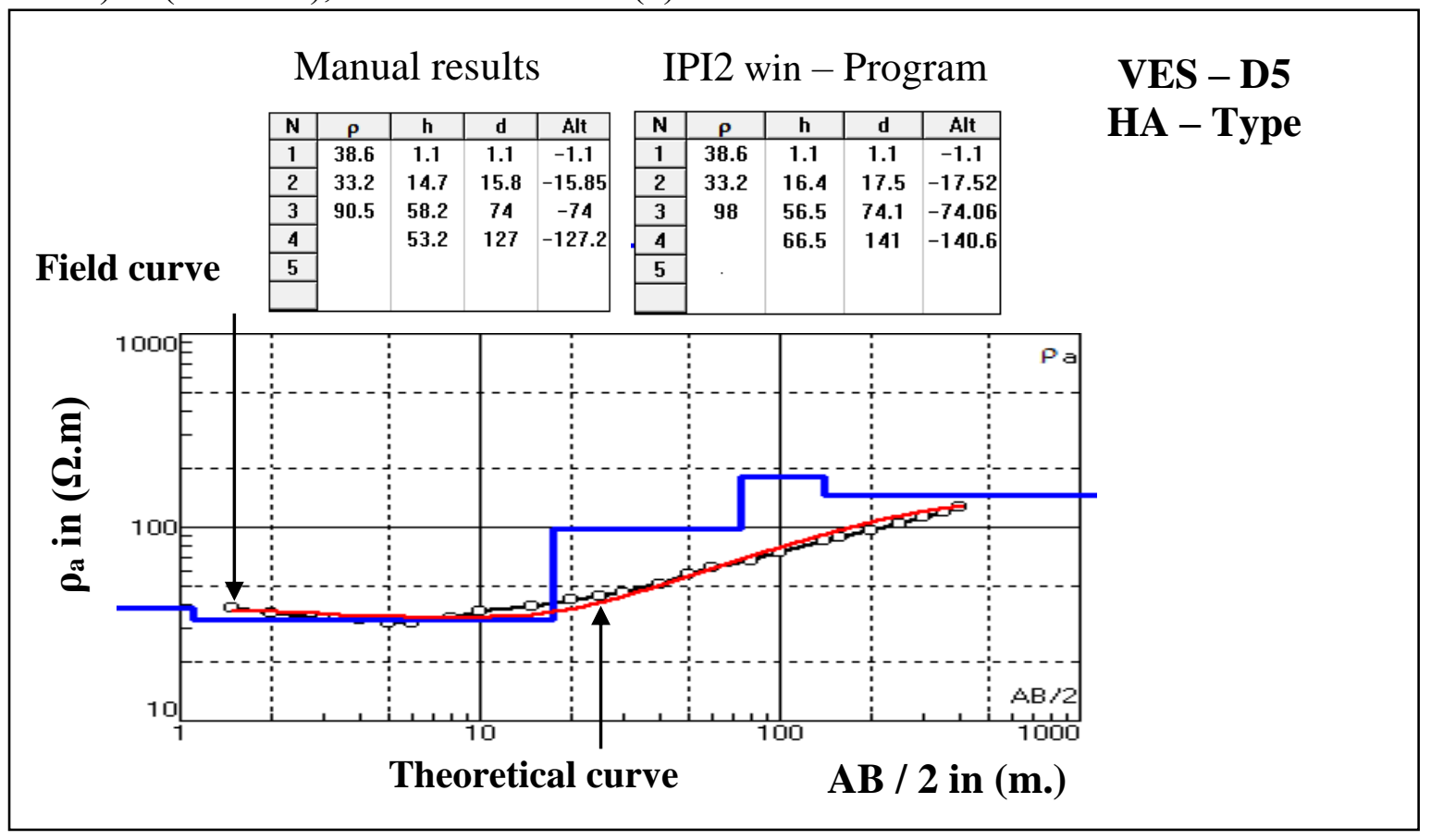

Fig.(4) Shows Inverse modeling output of IPI2 win-Software program and manual interpretation for VES - D5 of (HA) type 


\section{Result of porosity and hydraulic conductivity evaluation by empirical equations}

5.1 porosity estimation from empirical porosity-resistivity equation

(Amin, 2008) was deduced the positive linear relation between aquifer porosity and the measured resistivity from (8) pumping test wells assurance relation coefficient $\left(\mathrm{R}^{2}=0.9827\right)$ in the continued Zharazoor basin of the studied area the formulated relation is given by the following equation.

$$
\phi=0.2637 \rho+11.312 \cdots \cdots \cdots \cdots \cdot(13)
$$

The direct porosity estimations from aquifer resistivity values calculated on the bases of the interpreted field data both manually and by applying computer program are measured reaiativity values within the range of ( $3 \Omega . \mathrm{m})$ to (102 $\Omega . \mathrm{m})$, then by substituting of aquifer resistivity values in equation (13) the deduced aquifer porosity distributed along the studied area range between $(21 \%)$ to $(38 \%)$ as portrayed in Table (3). Abu Heen and Muhsen, 2017) had estimated Porosity to be in the range of (38\% - 52\%) with an average value of (46\%) which was close to the range of the present study.

\subsection{Hydraulic conductivity evaluation from empirical equation}

Based on estimating pumping tests for (18) wells. Amin, 2008 was deduced the positive hyperbolic relationship with relation coefficient $\left(\mathrm{R}^{2}=0.72\right)$ for hydraulic conductivity evaluation from measured resistivity of the aquifer from the corresponding following equation:-

$$
K=10^{0.0086} \rho-0.32
$$

Also by substituting of the calculated aquifer resistivity values in equation (14) the deduced and hydraulic conductivity values will range from ( $1 \mathrm{~m} /$ day) to $(4 \mathrm{~m} /$ day), shows the increasing of the both aquifer porosity hydraulic conductivity values from the top of uplifted subsurface layers underlying the piramagroon district toward both limbs according to increasing of rock fragments (gravel, pebble) and materials (sand) and decreasing of clay content overlying upper part of Middle Tanjero Formation.

\begin{tabular}{|c|c|c|c|c|c|}
\hline \multirow{4}{*}{ Profiles } & $\begin{array}{c}\text { VES } \\
\text { No. }\end{array}$ & $\begin{array}{c}\text { Aquifer } \\
\text { depth } \\
\mathrm{Z}(\mathrm{m} .)\end{array}$ & $\begin{array}{c}\text { Aquifer } \\
\text { Resistivity } \\
\rho_{\mathrm{r}}(\Omega . \mathrm{m})\end{array}$ & $\begin{array}{c}\text { Porosity } \\
\left(=0.2637^{*} \rho+11.312\right. \\
\phi(\%)\end{array}$ & $\begin{array}{c}\text { Hydraulic conductivity } \\
\mathrm{K}=10^{\wedge} 0.0086^{*} \rho-0.32 \\
\mathrm{~K}(\mathrm{~m} / \text { day })\end{array}$ \\
\hline \multirow{5}{*}{ Profile - A } & A1 & 83.0 & 62.8 & 27.8 & 1.6 \\
\cline { 2 - 7 } & A2 & 71.8 & 55.7 & 26.0 & 1.4 \\
\cline { 2 - 7 } & A3 & 58.0 & 50.6 & 24.6 & 1.30 \\
\cline { 2 - 7 } & A4 & 44.7 & 42.9 & 22.6 & 1.12 \\
\cline { 2 - 7 } & A5 & 40.5 & 37.5 & 21.2 & 1.00 \\
\hline \multirow{5}{*}{ Profile - B } & B1 & 95.7 & 72.8 & 30.5 & 2.02 \\
\cline { 2 - 7 } & B2 & 86.8 & 66.7 & 28.9 & 1.80 \\
\cline { 2 - 7 } & B3 & 75.0 & 58.4 & 26.7 & 1.52 \\
\cline { 2 - 6 } & B4 & 60.4 & 51.6 & 24.9 & 1.33 \\
\cline { 2 - 6 } & B5 & 45.7 & 40.8 & 22.0 & 1.07 \\
\hline
\end{tabular}


Table

\begin{tabular}{|c|c|c|c|c|c|}
\hline \multirow{5}{*}{ Profile - C } & C1 & 48.0 & 55.5 & 25.9 & 1.44 \\
\cline { 2 - 6 } & C2 & 57.8 & 62.7 & 27.8 & 1.65 \\
\cline { 2 - 6 } & C3 & 69.9 & 65.7 & 28.6 & 1.75 \\
\cline { 2 - 6 } & C4 & 84,6 & 70.6 & 29.9 & 1.94 \\
\cline { 2 - 6 } & C5 & 98.6 & 74 & 30.8 & 2.07 \\
\hline \multirow{5}{*}{ Profile - D } & D1 & 55.0 & 53.7 & 25.4 & 1.38 \\
\cline { 2 - 6 } & D2 & 69.3 & 65.6 & 28.6 & 1.75 \\
\cline { 2 - 6 } & D3 & 82.4 & 74 & 30.8 & 2.07 \\
\cline { 2 - 6 } & D4 & 95.4 & 87.5 & 34.3 & 2.70 \\
\cline { 2 - 6 } & D5 & 112.0 & 102 & 38.2 & 3.60 \\
\hline
\end{tabular}

Calculated aquifer porosity and hydraulic conductivity of the studied area

Increasing of the both aquifer porosity and hydraulic conductivity values from the top of uplifted subsurface layers underlying the piramagroon district toward both limbs clearly indicate of increasing of rock fragments (gravel, pebble) and materials (sand) and decreasing of clay content

overlying upper part of Middle Tanjero Formation. As a result of this the area of the piramagroon can be considered as the recharge zone for infiltrating surface rain water toward Tabin and piramagroon to subsurface saturated unconfined aquifer as shown in the following Fig. (5).

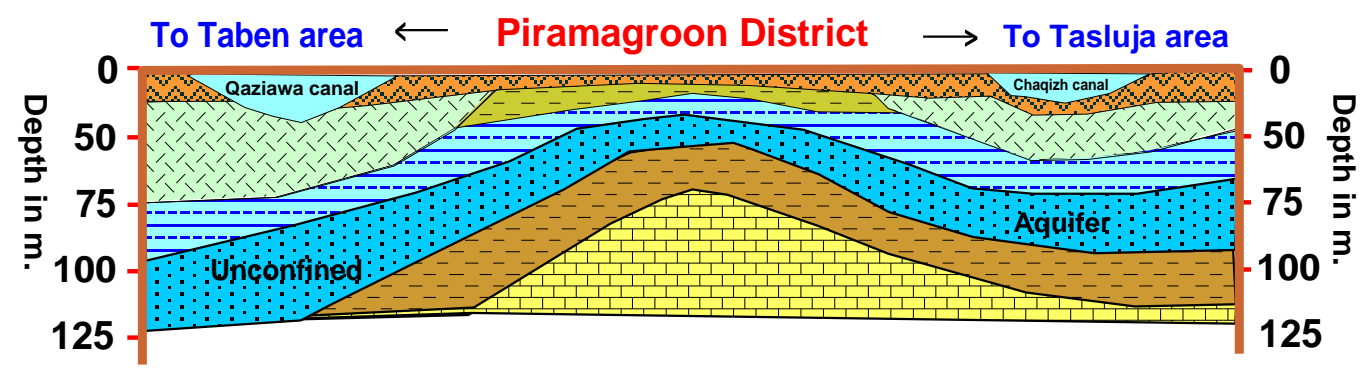

Fig. (5) Geological section shows aquifer situation under the studied area (Piramagroon district) drawn by Surfer 8, 2002

The estimated aquifer porosity values range along the studied area are range between (21\%) to (39\%) and from the porosity map the situation clearly indicates an increasing of porosity toward both limbs of the uplifted layers under Piramagroon district, as shown in Fig. (6). 


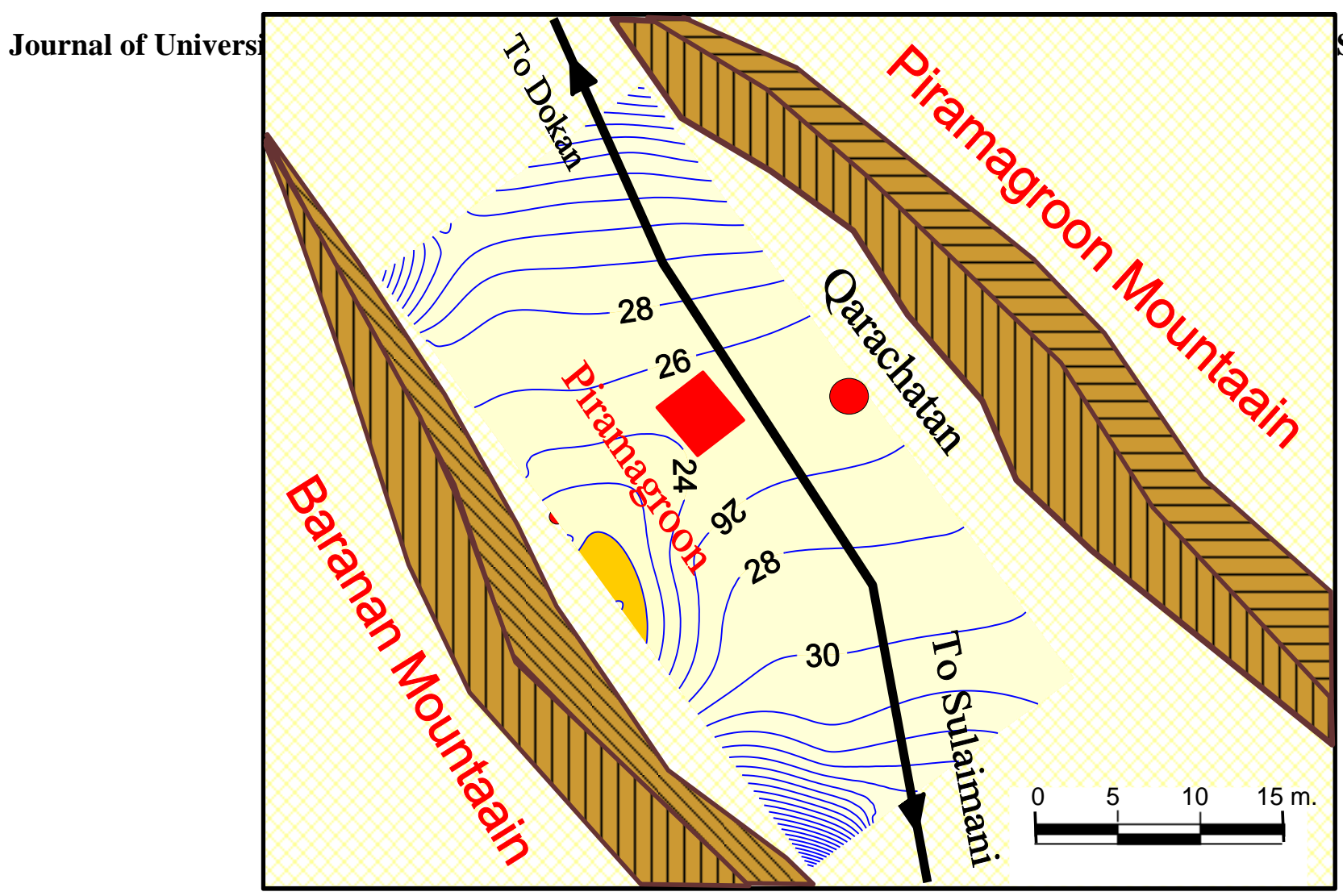

SN: $2410-1036$

Fig. (6) Aquifer porosity map of the studied area drawn by Surfer 8, 2002

The estimated hydraulic conductivity values range from $(1 \mathrm{~m} /$ day $)$ to $(4 \mathrm{~m} /$ day $)$ along the studied area from the hydraulic conductivity map the situation will also clearly indicates an increasing of hydraulic conductivity to ward both limbs of the uplifted layers under Piramagroon district, as shown in Fig. (7).

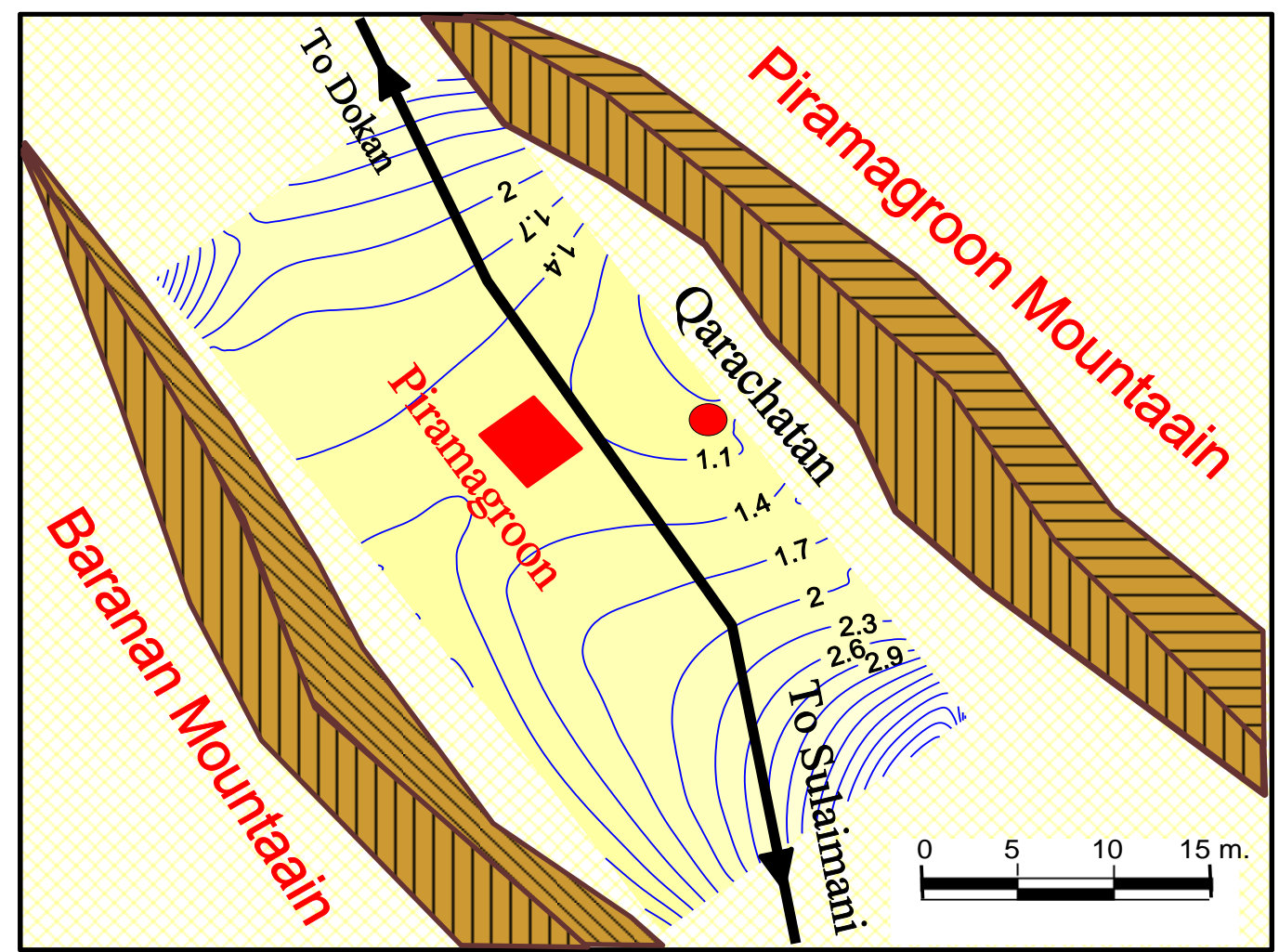

Fig. (7) Hydraulic conductivity map of the studied area drawn by Surfer 8, 2002 


\section{Conclusion:}

Since drilling of wells to determine hydraulic parameters is often prohibitively expensive, determining the aquifer parameters from VES results is a low cost-effective alternative. In a studied area four profiles were conducted, each profile includes of five VES points of measurements and each VES was interpreted using both manual and IPI2 win program for determining aquifer depth and resistivity. The deduced VES results in piramagroon basin are well coinciding with the relation conditions of the continuous adjacent Sharazoor basin. Then the calculated resistivity values range between (37 $\Omega . \mathrm{m})$ to $(102 \Omega . \mathrm{m})$ are substituted in the empirical porosity-resistivity equation in the study area shows the aquifer porosity distribution along studied area rang between $(21 \%)$ to $(39 \%)$.

Whereas substituting in the hydraulic conductivity-resistivity equation in the study area will show hydraulic conductivity values range from ( $1 \mathrm{~m} /$ day) to (4 m/day).

The calculated aquifer porosity and hydraulic conductivity values clearly show the applicability of the used equations in the studied area including presence of unconsolidated alluvial deposits of gravel and sand with decreasing of clay content toward both limbs of the uplifted subsurface layers overlying upper part of Middle Tanjero Formation.

Acknowledgment :- I deeply appreciates the general directorate of Sulamani municipalities for providing a static resistivity meter (SYSCAL Jr-Switch-72) for conducting this survey. 


\section{تقيم مسامية وتوصيل المياه للثزان الجوفي من المعادلات التجريبية بـاستخدام قياسات الجيوكهربانية المعودية في منطقة بيرمكروذ - شمال شرقة المراق}

قسم العلوم الاجتماعية، كلية التزبية الاساسية، جامعة السليمانية، السليمانية، إقليم كردستان، العراق.

Abdullakarim2004@gmail.com

\section{عبدالاله كريم أمين}

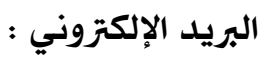

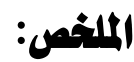

يتناول البحث تطبيق طريقة المسح الكهربائي العمودي بترتيب شلمبرجر كأسلوب منخفض التكلفة وأداة حقيقية في استكشاف المياه الجوفية, وهوالاسلوب الأكثر استخداما للمسح الهيدروجيولوجي للحوض الرسوبي. وتستخدم هذه الطريقة بانتظام لحل مجموعة واسعة من مشاكل المياه الجوفية والمعاملات الهيدروليكية مثل مسامية الخزان الجوفي في هذه الدراسة. ولذلك فإن الهدف من هذه الدراسة هو تقييم قابلية تطبيق وموثوقية المعادلة التجريبية التي تربط بين مسامية الخزان ومقاومتها الكهربائية، لهذا الغرض تم اختيارأربع مسارات المسح في منطقة بيرمكرون والمتكونة من تواجد تكوين تانجرو المغطاة بالترسبات الحديثة, ويتضمن كل مسارمن ست نقاط قياس المقاومة الكهربائية. وتم تفسير المنحنيات المقاومة الكهربائية باستخدام كل من التفسيراليدوي وبرنامج IPI2 win لتحديد مقاومة الخزان الجوفي وكذلك سمكه وعمقه. ومن ثم تم تعويض قيم المقاومة المحسوبة في معادلتي علاقة المسامية وتوصيل المياه بالمقاومة. حيث استنتج بان القيم المسامية المستخرجة من تطبيق المعادلة المسامية من مقاومة الخزان الجوفي (102 S.m) (الى (10.m) و مسامية الخزان

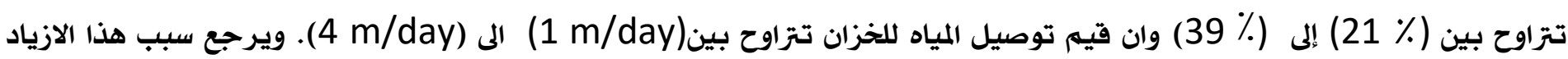
من قمة تركيب الطية الواقعة تحت ناحية بيرمكرون باتجاه الشمال الى قرية قازياوا وكذلك باتجاه الجنوب الى قرية جقش الى التناقص نسبة الطين داخل الترسبات المتجوية المتبادلة مع الترسبات الخشنة الحديثة الغير متماسكة من الرمل والحصى الواقعة فوق الجزء العلوي لتكوين تانجروالاوسط.

الكالمات المفتاحية؛ المساميةالخران (\$)، توصيل المياه للخزان (K)، المعادلات التجريبية ل (\$) و (K)، مقاومة الكهربائية العمودية (VES) 


\section{References:}

Abdelaali R., Abderrahim B., Mohammed B., Yves G., Abderrahim S., Mimoun H., and Jamal S., 2014 : Relationships between porosity and permeability of calcarenite rocks based on laboratory measurements, J. Mater. Environ. Sci. 5 (3), PP. 931-936.

Amin A. K., 2008 : Aquifer Delineation and Evaluation of Hydraulic Parameters from Surfacial Resistivity Measurements in Sharazoor Basin, North East Iraq, Ph.D. Thesis, college of Science, Univ. of Baghdad Unpublished 181p.

Archie, G. E., 1942 : The electrical resistivity log as an aid in determining some reservoir characteristic. Trans. Am. Inst. Min. Eng., Vol. 146, PP. 54-62.

Batayneh, A. T., 2009 : A Hydrogeophysical Model of the Relationship between Geoelectric and Hydraulic Parameters, Central Jordan. Journal of Water Resource and Protection Department of Geology and Geophysics, King Saud University, Riyadh, Saudi Arabia.

Boüwer, H. 1978 : Ground water hydrology, McGraw-Hill Book, New York, 480P.

Burnard, J., 2003 : Short note on the depth of investigation of electrical methods.

Daves, S. N., and Dewiest, R. J. M., 1966. Hydrogeology, Join wiley and Sons INC., New York.

De Block , 2013: An alternative method for estimating the porosity and the permeability of (potential) geothermal reservoirs using magnetotelluric data; A case study of the Sherwood Sandstone Group in the Lough Neagh Basin, Northern Ireland, M.Sc. Thesis, Department of Earth Sciences Utrecht University, Utrecht, The Netherlands .

Deming, D., 2002: Introduction to hydrogeology, McGraw-Hill, Higher Education, USA, 468P.

Fatoba, J. O. , Omolayo S. D., Adigun, E. O., 2014 : Using geoelectric soundings for estimation of hydraulic characteristics of aquifers in the coastal area of Lagos, southwestern Nigeria, International Letters of Natural Sciences 6, PP. 30-39.

Fetter, C. W., 1998: Applied Hydrogeology, Second Edition, Merrill Publishing Company, Columbus, Ohao, 592P.

Karim, K. H., 2004: Basin analysis of Tanjero Formation in Sulaimaniya Area, NE - IRAQ, Unpublished Ph.D Theses, Geo. Dep., College of Science, University of Sulaimaniya.

Kruseman, G. P. and De Ridder, N. A., 1994: Analysis and evaluation of pumping test data, International Institute for land reclamation and improvement. P.O. Box.45, 6700 AA Wageningen, The Netherlands, 377P.

Nelson, S. A., 2015: Groundwater (Physical Geology), Tulane University Page 1 of 11 http://www.tulane.edu/ sanelson/eens1110/groundwater.htm. 
Nicaise, Y., Gerard F. A., and Flavien D., 2013: Hydrogeophysical estimation of an unconfined sandy aquifer parameters using gravimetric and geoelectrical methods, Applied Science Reports, 2 (1) : 1-9, (C) PSCI Publications.

Nimmo, J. R., 2004 : Porosity and Pore Size Distribution, U.S. Geological Survey, Menlo Park, CA 94025, USA, in Hillel, D., ed. Encyclopedia of Soils in the Environment: London, Elsevier, V. 3, PP. 295-303.

Odong. J., 2007: Evaluation of empirical formulae for determination of hydraulic conductivity based on grainsize analysie. Journal of American Science, 3(3), Schoole of environmental studies, China University of Geoscience, 388, Lumo road, Wuchange, Wuhan, Hubei, P. R., China.

Surfer 8.01, Golden software inc., 2002: Surfer mapping system, 14th street, Golden Colorado.

Sri Niwas, and Lima O.A.L., 2003: Aquifer Parameter Estimation from Surface Resistivity Data. Ground Water 41 (1), PP. $95-99$.

Sri Niwas, and Muhammed C., 2012 : Equation estimation of porosity and hydraulic conductivity of Ruhrtal aquifer in Germany using near surface geophysics. Elsevier, Journal of Applied Geophysics 84, PP. 77-85.

SYSCAL Jr. Switch -72, 2002: One and Two dimenssion Resistivity- meter system, IRIS - France.

Todd, D. K. and Mays, L. W., 2005: Groundwater Hydrology. John Wiley and Sons, Inc., PP. 125-142, US.

Urumovic, K, Urumovic, S. K, 2016: The referential grain size and effective porosity in the Kozeny - Carman model, Hydrology and Earth System Science (EGS), Copernicus Publications on behalf of the European Geosciences.

Vukovic, M., and Soro, A., 1992: Determination of Hydraulic Conductivity of Porous Media from Grain-Size Composition. Water Resources Publications, Littleton, Colorado. 